\title{
Management of \\ "technology push" development projects
}

Prof. Dr. Cornelius Herstatt

Dipl.-Kfm. Christopher Lettl

August 2000

Paper No. 5 


\title{
Management of "technology push" development projects
}

\author{
Prof. Dr. Cornelius Herstatt and Dipl. Kfm. Christopher Lettl \\ Technology and Innovation Management at the Technische Universität Hamburg-Harburg \\ Schwarzenbergstrasse 95 \\ D-21073 Hamburg
}

\begin{abstract}
:
Discussion of "market pull" versus "technology push" approaches in the field of business innovation research has followed a certain trend. The empirical research undertaken until now has been concerned in particular with the question of how each of these approaches differently influence the subsequent success of the innovation.

We do not wish to continue this discussion in our paper, rather we assume that both approaches are justified depending upon the importance of the relevant innovation source, the desired degree of innovation and the respective characteristics of the industry in question. We concern ourselves with the characteristics that result in the "technology push" for the management of innovation projects and what implications can be derived from practical project management organization. In doing so, we concentrate upon all market-related activities, in particular the identification and verification of application areas for new technology.
\end{abstract}

After contrasting the various characteristics of the "technology push" and "market pull" approaches, the market-related characteristics of "technology push" projects are outlined. In this context, current instruments and methods of qualitative market research are introduced and their usefulness discussed. In addition, organizationalstructural aspects as well as strategic and operative aspects of "technology push" project management will be highlighted.

Key words: "technology push"-project management-marketing

\section{Introduction}

Many companies find themselves under increasing pressure to produce innovative products and services, in ever-shortening development cycle-times, and in a rapidly changing and increasingly competitive market place. As an effective instrument to aid in realizing these seemingly contradictory demands, goal-orientated project management is highly regarded both in academic circles as well as in industry. Herewith it is to note that the success of an innovation project strongly depends on the degree to which its management is aligned with the specific situative context. A relevant context factor of innovation projects is if the innovation is initiated primarily through a "technology push" or a "market pull".

This paper examines more exactly the management of innovation projects with a "technology push" arrangement. With this in mind, the following section defines and differentiates the concepts of "technology push" and "market pull" based on specific criteria. A morphological 
"criteria catalogue" is then presented. Section 3 describes the market-related characteristics and problems of technology-induced innovation projects with the aid of case studies. In this context, current instruments and methods of qualitative market research are introduced and their usefulness discussed. Finally, organizational-structural aspects (centralized versus decentralized structure), strategic, in particular portfolio-related as well as technical management aspects (project validation, team structure) are discussed. We also illustrate this discussion with current examples of innovation management from practice.

\section{2. "Technology Push" versus "Market Pull" as innovation driver}

A critical question with respect to the strategic direction to be taken by a company at the R\&D and marketing interface is if successful innovation can be induced better through "technology push" or through "market pull". A "technology push" describes a situation where an emerging technology or a new combination of existing technologies provide the driving force for an innovative product and problem solution in the market place. In certain cases it is even possible that the new technology, when it is transformed into radical product or process innovations, achieves it own market position. This new technology or technology combination could come into being in a research and development unit, an application orientated development unit, a combination of both or a cooperation extending beyond the confines of a single company's R\&D unit.

Conversely, the term "market pull" implies that the product or process innovation has its origins in latent, unsatisfied customer needs in the market place. The identification of these needs occur first and are then followed by the required development activities (Chidamber; Kon, 1994).

While these simple descriptions reduce the essential difference of both approaches to lie in the innovation's place of origin ( $R \& D$ versus market place), closer observation reveals that a whole range of differences follow-on from this basic differentiation:

- Potential market applications for a "technology push" strategy are essentially unknown, whereas the knowledge about the areas of need in a "market pull" situation can be directly taken as a starting point for these potential applications. (Pfeiffer, 1992).

- "Technology push" innovation projects generally possess higher market uncertainty. This difference implies that both approaches demand completely different methods to win market information.

- A "technology push" situation implies more the use of anticipatory, exploratory market research methods (e.g. scenarios, Delphi-studies, road mapping), whereas a "market pull" allows the use of information from predominately conventional market research concepts (Lender, 1991).

A further important difference can be seen in the innovation degree pursued: "technology push" strategies strive for "breakthrough" innovation through their massive R\&D investments, that in part involve basic research activities (Souder, 1989). Conversely, a "market pull" approach leads to more incremental innovations, based on the existing product range. Therefore the time involved with both strategies can also differ greatly. A "technology push" innovation can encompass a time period of over ten years, whereas a "market pull" project is generally more a short-term activity due to its higher market focus. 
Based on the ideas discussed thus far, it would appear that "technology push" -induced innovation projects often posses a significantly higher technological uncertainty in comparison to "market pull" projects. This increased uncertainty can, in turn, have implications for the organization structure (e.g. cooperations to share risk and resources with "technology push").

Figure 1 contrasts the dependence between the degree of innovation, R\&D effort, and development time as well as the market and technology uncertainty between "market pull" and "technology push" projects.

Insert Fig. 1 here

Figure 1. R\&D-Investment, Degree of Innovation and Development Time of "Technology Push" and "Market Pull" projects (Source: own depiction)

Both basic approaches assume occupy positions on a continuum and when applied in their pure forms in practice contain inherent dangers:

- The "technology push" strategy leads not infrequently to a "lab in the woods approach" by Research and development who become both spatially and organizationally isolated and in doing so lose market perspective.

- "Market pull" strategies often lead to the "face lifting" of an existing product without questioning the technological relevance behind the development.

The sharp delineation of pure "technology push" and "market pull" approaches made here is scarcely found in today's innovation practice. More often than not, innovations consist of hybrids of both concepts (research and development, marketing/sales, assembly and service all contribute in various measures to innovation projects) where, depending on the phase of the innovation project being considered, the specific tasks are mainly carried out by individual functional groups. This depends partly also on the nature of the work division of the innovation process in technologically challenging products and services.

The nature of innovation projects is often difficult to clearly categorize, not only due to the respective positioning of the activities throughout the process phases yielding "mix" projects displaying both "technology push" and "market pull" characteristics, but also due to other phenomenon:

- In practice, innovation projects are often initiated by individuals or groups in various functional areas within the company but are then taken over by those from another area. It is therefore possible, for example, that a recurring customer reclamation can lead to a marketing/sales-initialized project. This would then generally lead in turn to the product being optimized through application development/construction (market pull-initiated product innovation). If, due to the available technology, no (further) product optimization is possible, the functional groups involved often soon reach their limits. This can once again initiate a development project, at the end of which, a completely new product is created and one that radically changes the context in which the customer applies it. This process would take usually several years for sophisticated products, after which it may be nearly impossible to unequivocally categorize the resulting innovation as being either 
"technology push" or "market pull". Expressed differently, "technology push" projects initiate "market pull" projects and vice versa.

- “Technology push" versus "market pull" are also often a question of interpretation. "Innovation legends", which often can't stand up to critical examination, come into being as a result of people not presiding over the complete picture. An example of this would be 3M's "Post-it". Rarely has a product in recent times been mentioned in publications and case studies as often as the "Post-it" (e.g. by Nayak; Ketteringham, 1986, pg. 29). The "Post-it" is described by $3 \mathrm{M}$ on occasions as a result of a "technology push" and in other cases as reaction to market needs. Entering the market in the early 1980s, it has been developed further into innumerous formats (variations exist in size, shape, color, and application areas). Who could possibly still determine the original source of the innovation and who initiated this single innovation and successfully introduced it to the market place?

Despite the difficulties outlined here in determining in an individual case, and after the fact, whether an innovation is of "technology push" or "market pull" origin, the problem remains for those companies whose intent it is to initiate a product or process innovation on the basis of a technological development. This is particularly relevant for companies wishing to build their innovation specifically upon their technological basis, e.g. biotechnology companies.

In the following section, we will concentrate upon such examples where companies knowingly initiate innovations based on their research and development ("technology push"). We hold that an important prerequisite for successful management of innovation projects (Section 4) is the exact understanding of characteristics and problems associated with the marketingside of such technology-induced development. We therefore will highlight the marketingrelated aspects in the following section. We discuss here the "state-of-the-art" techniques and instruments of qualitative market research and, in particular, those that identify possible application areas and estimate their potential more exactly whilst still in the early phases of the technology development.

\section{Market-specific characteristics and problems of technology-driven development projects}

\subsection{Unknown Application Fields}

Market-specific characteristics and problems of technology-driven development projects stem from the fact that the innovative technology will leave the usual target markets, which make up the existing market place, in favor of completely new application fields. These new fields must first be identified in what it is an exploratory and creative process, demanding different competencies, methods and information in comparison to the optimization of existing market segments (Wood; Brown, 1998; Lynn; Heintz, 1992; Hamel; Prahalad, 1991). The identification of possible application fields requires an examination of abstract functions where the emerging technology (or technology combination) can compete. The people involved in such a process must posses both the capability and desire to be able to extrapolate from the current market situation as well as bringing into the analysis all potential application functions where the technology could play a role. The practical realization of these demands often leads to considerable problems for innovation management. The following are some examples to illustrate this problem: 
- When new technologies are developed, for example an application-oriented development at a company's product division, the prospective points of entry into the market place considered for the new product or service are often limited only to those which the division currently serves (e.g. as complimentary or substitution technologies). An extensive exploration beyond the division's boundaries to other company/organizational areas or even as a starting point for new business divisions escapes most in this situation. The reasons for this sort of omission are many and may include a lacking sense of responsibility, inadequate incentive systems, insufficient techniques or operative problems such as time pressure and insufficient resources.

- The search for economically attractive application fields for emerging, new technologies is no trivial problem. Often there exists a lack of ideas and knowledge within the company about such application areas. Even when these areas can be roughly specified, the determination of their relevance for the technology is rarely a task to be delegated. The analysis can often be at least partly carried out by the technology development personnel when it is concerned with one or just a few fields. However, often for each new type of technology, many potential application fields present themselves. A detailed, all-encompassing examination of the technology's applicability would usually over-extend such a team. Even if this can be achieved once by the team, it is unlikely that the knowledge would be able to be continually updated in response to the changing dynamics in the different industries involved.

- The analysis of the "fit" of the innovative technologies in existing product/market combinations is done mostly through a qualitative or quantitative functional description of the technologies. This is often analyzed based on "critical success factors" in the application area in question. If one or more of the technology's functions provide a measurable contribution to the fulfillment of these success factors, then this will be taken as an indicator for a probable, subsequent market acceptance. Particularly with longer-term development projects, this method of static examination of the technology's difficult to quantify functional performance and the previously mentioned market dynamics often becomes impossible. Another aspect is that this method of examination approximates a market analysis of known application areas and products. The new technology/technology combination however could create completely new product/market combinations for which it is practically impossible to determine critical success factors, as there exists no experience on which to base such factors. The following example illustrates this: Only through the combination of different technologies was it possible at Siemens to offer a satellite based navigation system. The testing of the different functions of the individual technologies involved based on the salient product characteristics in this business segment proved impossible as the market segment at that stage was yet to be created.

\subsection{Customer-specific characteristics and problems}

The inclusion of customers into "technology push" development projects in order to reduce the great market uncertainty that exists as a result of a lack of market knowledge, often proves to be problematic. It is often the case in technology induced development projects that it is not completely clear exactly who the prospective customers are. Those responsible for marketing in "market pull" innovations often possess very detailed knowledge about the profile of their customers and their needs. In contrast, a key activity in technology-induced innovation projects is the determination of the target market in question as well as their preferences. 
Even if the development project team develops an initial impression from potential customers, the customers are often not able to articulate their preferences with regard to such an abstract technology concept, as they lack experience with the technology's potential applications (the barrier of "missing skills"). Even if the customers possess the required skills, psychological barriers exist (the barrier of the "missing motivation") accompanied by a completely different set of problems and where, from the customer's point of view, no requirement exists for them to be dealt with (Veryzer, 1998 a; O'Connor, 1998; Bower; Christensen, 1995).

In addition, technological innovations often bring with them the need for a change in behavior for the customer that is often perceived as being "uncomfortable" by the customer and makes intensive re-schooling unavoidable (Lynn et al. 1996; Urban et al, 1996). If a project's future was to be determined therefore only on the basis of the customer's "voice", then the result would often be the abandonment of the envisioned technology-driven innovation project due to these cognitive and behavioral-related barriers encountered. An example of this can be in the years where leading US radiologists adamantly advised General Electric not to develop Computer Axial Topography any further, a technology that would later and till this day is described as a breakthrough innovation (Lynn et al., 1996). Why? The doctors questioned saw no need for a replacement for the traditionally used X-ray technology. GE fighting against not only an established technology with its CAT breakthrough but also against decades-old behavioral patterns. New doctors were (are) learning to work with the X-ray machines at university, and this knowledge accompanied (accompanies) these doctors throughout their careers in their practical work as well as their research. Another example is that of the US-company Corning, who succeeded with third development of the "Optical Fiber" a breakthrough innovation, only because they ignored the negative assessment of their most important customer, AT\&T, and continued working on this technology (Lynn et al., 1996). Therefore the further away from market introduction a technology is the more difficult it is to know when customers are "mature" enough for a technological innovation or when problems from a technological point of view are eliminated.

From this, one could conclude that talks with target customers in the initial stages of a technology-driven innovation with the aim of ascertaining there likely future product acceptance and purchasing preparedness usually must lead to the termination of these sorts of projects. In our opinion, this hypothesis goes too far; in this context, we consider the following two questions to be of utmost relevance:

1. What contribution do customers, i.e. people who buy and use products, make to a development -driven project and at what points in the overall development process?

2. Can companies profit significantly more from the inclusion of customers or users from analogous application fields?

Von Hippel, in the early 1980s, had already suggested the concept of so-called Lead Users, who differ greatly, with respect to their innovation potential, in comparison to average customer/users. Von Hippel showed, through the example of the development integrated circuit that such Lead User manufacturers can deliver pure consumer data as well as complete new product conceptions and designs. Von Hippel described these users through the following two characteristics (von Hippel, 1988):

- Lead users face needs that will be general in marketplace-but face them months or years before the bulk of that marketplace encounters them, and

- Lead users are positioned to benefit significantly by obtaining a solution to those needs. 
The first characteristic expresses the fact that the lead user possesses the required "real world" experience with future market needs. Lead users are experienced with conditions that, for the majority of product users, still lie in the distant future; they are the trendsetters in their field and can be considered the expert source for different product or process-related information. The second characteristic is based on the assumption that users who stand to benefit (economically) from the solution to a particular problem are more interested in taking an active role in finding the solution in comparison with users who want experience any great benefit.

It is important to note here that lead users are not only or must not only be found in the target group of (future) product customers. Basically there are three different categories of lead users recognized:

1) lead users in the target group of (future) products and applications;

2) lead users in analogous markets for similar products and applications;

3) lead users who possess particular attributes or characteristics that are relevant for the target market;

To illustrate this, another example, once again from the X-ray technology field (taken from von Hippel et al., 1998): An important manufacturer of X-ray equipment had decided to form a Lead User group with the purpose of creating new product concepts. One of the companies of those assembled identified two relevant trends for X-ray equipment: 1 . higher picture resolution and 2. better processes to identify "weak" patterns, like tumors in their early stages. In their search for suitable Lead Users, the company stumbled upon lead users from the three named categories:

1. lead users as part of the target group for X-ray equipment; this involved X-ray doctors who due to their intensive work and experience with X-ray equipment presented themselves as particularly well qualified.

2. lead users from analogous product areas; this group involved development engineers who had specialized experience with the picture transference in electron microscopes for example from the semi-conductor industry.

3. lead users possessing special, relevant problem or product attributes. Such lead users were, for example, specialists who have dealt with acoustic patterning problems.

The question remains whether with this group of lead users the basis for the CTM technology (see Section 3.1) could have also been found. We can only speculate. However the probability would have been rather small as the initial investigative question was a completely different one.

The inclusion of customers into technology-driven innovation projects can, in our opinion, neither be completely rejected nor supported. The empirical innovation research has at least proven the existence and relevance of lead users in many industries (Shah; 2000; Lüthje; 2000; von Hippel et al., 1999; Herstatt; von Hippel, 1991).

\subsection{Limited suitability of conventional market research methods}

Next to the outlined customer-related problems, conventional market research methods also often prove to be of little help in removing the inherent uncertainty of technology-driven in- 
novations. Conventional market research methods such as customer surveys and focus group discussions are orientated for a shorter-term investigation (orientated at "today's" customer) and, with this bias on existing product programs, lead to more incremental developments. The market orientated information need of technology-driven innovation projects is, in contrast, arranged for the future (orientated at "tomorrow's" customers and markets) and focuses on radical innovation. Technology-driven innovation projects demand therefore reinforced explorative and anticipative market research methods that are designed to determine current customer needs (Deszca, 1999; Lender, 1991).

"Roadmapping" is described as a process that, with help from experts via workshops, anticipates future development in technology and products (up to 15 years) systematically and that can be visualized with the aid of "temporal paths" (the "roadmaps") (Vinkemeier, 1999). These "roadmaps" can be projected from the present to a point in the future or can be retrospectively developed based on previously suggested scenarios. This method proves to be particular powerful as an indicator of future trends when the "technology roadmap" is aligned with the "product roadmap" via so called "technology trees" (Groenveld, 1997). From this it is possible to determine what technology a particular future product generation will require. The removal of "white spots" in the "technology roadmap" can be achieved through R\&D cooperations, technology acquisitions or in-house developments. In this way "roadmapping" supports the decision making process of strategic R\&D priorities and increases the awareness of the personnel from $\mathrm{R} \& \mathrm{D}$, production and marketing involved in the creation of future development opportunities to technical discontinuities that often ring in a new product generation. Examples of this being applied to be found in the literature include those at Siemens AG where the technology and product roadmaps have been produced and used in a large variety of business divisions (Mirow, 1988; Weyrich, 1996

Another relatively new market research method that was conceived with the market-related characteristics of technology-induced development projects in mind, is the so-called "Information Acceleration" (Urban et al., 1997). Applied at the prototype stage, "Information Acceleration" utilizes the potential of virtual reality and other multimedia applications in order to transfer customers into the envisioned future context as authentically as possible. Such simulations allow the test-customer to obtain "virtual" experience with the innovation that is based on the new technology concept. In addition the customer's future buying decision would be simulated through the provision of information sources (newspapers, magazines, other customers, sales personnel etc) on a Multi-Media PC. Once the customer has obtained an impression of the innovation, if necessary through the testing of "real" prototype, their perceptions, preferences and buying intentions are collected.

Alongside the generation of customer feedback, the goal of "Information Acceleration" is to determine, as accurately as possible, the future purchasing behavior of the consumer in order to aid in market trend prediction of the technology-induced innovation (Rosenberger; de Chernatony, 1995). "Information Acceleration" is especially well suited for technologyinduced, breakthrough innovations due to it allowing the customer to obtain "virtual knowhow" through projecting the new technology into the future and the simulation of future products. In addition, "Information Acceleration" allows the active integration of the customer into the very early phases of technology induced development projects. Through this, valuable information can be generated leading to a stronger customer and market-oriented technology development. "Information Acceleration" also precipitates a shortening of the development time as the use of "Virtual Prototyping" can often make much of the long-winded and involved construction of real prototypes as well as the subsequent market research cycles redundant (Adamjee, 1994). "Information Acceleration" also stands in agreement with the empirical finding that successful technology-driven development projects excel through early 
prototyping, that is the basis for the delivery of customer feedback. The description of "Information Acceleration" use in practice is rarely to be found in the literature. General Motors, for example, used it in their vehicle development (Urban et al., 1997). The following points show some inherent problems with "Information Acceleration":

- The introduction of a "Information Acceleration" project brings with it significant costs. These lie at about $\$ 100000$ per test group;

- Preparation, introduction and conclusion of an "Information Acceleration" project demands a substantial planning phase (many weeks to months); companies often find it difficult to commit the required resources.

A possible alternative to "Information Acceleration" combines the use of virtual reality technology to 3-dimensional depiction of innovative technology in either one-off products or product systems (Rosenberger; Cherantony, 2000). The problem here is that this type of technique is most commonly used at present within the scope of market research i.e. at a time when the actual development work is often nearly complete. The use of virtual technology and the associated software and hardware systems for creative management of the very early phases of the innovation process has not advanced far in practice (further to this: Herstatt/Dockenfuss, in preparation).

\section{4 "Probe and Learn" in place of "Stage-Gate Processes"}

Lynn et al. show through case studies that an iterative "Probe and Learn" process is best suited to the peculiarities of "technology push" projects (Lynn et al. 1996). "Probing and Learning" implies the confronting of potential customers with not necessarily mature prototypes in the very early stages of a project and thereby, through the acquired "market" knowledge, gain information for the development of the subsequent prototypes. The learning curve that results through the iterative nature of the process successively removes market and technological uncertainty and contributes to the integration of the customer in the development process.

The experimental and iterative nature of "Probing and Learning" differentiates it greatly from the so-called "Stage-Gate" innovation processes that proceed by way of a sequential progression of individual phases (e.g. idea generation, concept development, development, prototype/market test, market introduction). Such "Stage-Gate" processes have proven themselves to be better suited for market-driven, incremental innovations (Cooper; Kleinschmidt, 1990), whilst for technology-induced break-through innovations they may be counter-productive due to their inherent uncertainties and risks (Dermott, 1999; Song; Montaya-Weiss, 1998; Veryzer, 1998 b; Rice et al., 1998; Lynn et al., 1996).

A flexible "probe and learn" process based upon an iterative learning curve requires an information exchange, initiated very early in the process, at the interface between R\&D and marketing. Such an early integration of $R \& D$ and marketing occurs rarely in technology-driven projects in practice. More commonly, the marketing personnel are involved only just before market introduction (see Figure 2). 
Figure 2: $\quad$ Involvement of Technical Personnel and Sales/Marketing

Personnel in the Project Life Cycle

(Source: own depiction)

This observation may also depend upon the high potential for conflict that exists, in particular with technology-driven development projects, between both departments. Marketing, in its understanding of its traditional role, strives for quick market capitalization, a property that is however often lacking in technology-induced innovation. Therefore a successful "probe and learn” process also demands a change in marketing's understanding of their role.

"Probing and Learning" has however other effects. For the technology-driven development project not to be discontinued after the first or second piece of negative customer feedback (a likely reaction due to the lack of experience and know-how with the new technology, the turning away from the conventional technology as well as the change required in their own behavior), the project must occupy a central, strategic position of importance within the company and enjoy the associated support from the senior management. The top management especially, carries the responsibility for the culture and environment that allows the development team to think creatively and unconventionally as well as being able to learn from its mistakes. The development team itself requires both a high capacity and will to learn in order for the learning loops to capitalize upon the project's inherent potential (Lynn, 1998).

Figure 3 summarizes the market-related characteristics of technology-induced development projects and contrasts this with the "market pull" arrangement.

Insert Fig. 3 here

Figure 3: $\quad$ Market-related characteristics of technology-induced development projects (Source: own depiction)

The sometimes large difference, at least from a market-related point of view, that exist between both project types leads to the assumption that the selection of project management style should also differ according to project type. In the following section we present some thoughts that stem from the implications for the practical management of the outlined marketrelated characteristics of technology-driven development projects. In doing so, we concentrate on organizational/structural, strategic as well as technical management aspects.

\section{Some organizational-structural, strategic and technical management as- pects of the management of technology-driven projects}

\subsection{Initiation and introduction of technology-driven projects: centralized versus decen- tralized organizational placement}

The initiation and introduction of technology-driven projects can occur within a centralized, decentralized, mixed central-decentralized R\&D as well as in combination with research and development partners from outside the company (see also Section 3). An ideal organizational structure for this type of innovation is unlikely to exist. However, if a project is particularly concerned with ensuring the personnel involved can extrapolate from the current market segments effectively and identify as many potential applications as possible where the new tech- 
nology can play a role, then there is much to be said for a decentralized organizational structure. Further characteristics of such an organizational form are flexibility, a flat structure and (part-) autonomy (Bleicher, 1991).

A clear example for this kind of organizational structure can be seen at the Mannesmann Pilot Development (mpd), founded in 1992. In cooperation with the Vodafone/Mannesmann companies, their main activity consists of examining the newest technologies emerging from the company and to analyze them for their application potential. In contrast to other organizations, Mannesmann possesses no central R\&D unit and the innovation plans of the individual groups are initiated by the respective development department belonging to each. In order to secure the innovations beyond these group divisions, the mpd created a type of "idea space", in which the innovations are matured for market introduction between three to seven years. The mpd is a $100 \%$ owned daughter of the Vodafone/Mannesmann AG and answers directly to the technical board of the central concern. It is made up of a highly qualified team of about 70 personnel stemming from engineering, science, IT and finance fields who work in different project teams together. The technical foundation of each project is monitored constantly, both internally and externally. The practical realization of a project requires a highly motivated, cooperative, cross-functional team stemming from all over the organization. Many positive outcomes have resulted from the mpd since its conception. This is evidenced through the many patents and prototypes as well as new business areas through to the founding of new businesses. The following success factors have been observed as operating within these company-wide innovation teams charged with the exploration of new technologies: (Kainzbauer; Kaelber, 1998):

- Cross-functional team work

- Integration of lead users in the development process

- Ensuring the provision of time and space for "free thought", at the same time consequential project planning through milestones and deadlines

- Support for the evaluation of the planning through efficient information transfer such as the internet and data bases

- The spatial and temporal arrangement of teams to allow for and accelerate direct, informal communication

- Support of the teams through the presence of high ranking promoters such as board members or directors

From our point of view, the mpd represents a particularly promising organizational structure where the exploration of possible new, innovative application areas can be clearly targeted.

The Daimler-Chrysler organization has in the mean time also taken a similar approach as had Hüls AG. These activities also allow the recognition of the positive effects of large-scale mergers ("megamergers"). For example, in this way the Hoffmann-La-Roche group (therapeutics), through its takeover of Böhringer Mannheim (diagnostics), ensured entrance to a whole new business are with significant innovation potential (combined diagnostic/therapeutic business). At present, these companies are developing products that would allow patients to independently diagnose particular illnesses and to take the appropriate action.

\subsection{Establishment of technology-driven projects within the framework of a new port- folio understanding}


The composition and dynamic adaptability of the project portfolio, from a risk and timing point of view, is in technology-driven companies of critical importance. The project definition (input variable) is naturally particularly critical as the high technological and market uncertainty associated with "technology push" projects results in an extremely high failure rate of projects particularly in the early phases of product/process development being. In the pharmaceutical industry, for example, one calculates with a realization rate of 1:1000.

The definition of a project can be looked upon as being a multi-dimensional decision making process under conditions of high uncertainty. The attractiveness of the project should be estimated at the earliest possible point in time, ideally at the time of project initiation. In practice, different theoretical assessment approaches are used in order to determine the total project attractiveness, based on different attractiveness and risk criteria (e.g. yield expected to be derived from expected market share, turnover and costs; risks derived from the risk of commercalization, technical risks or substitution risks). These approaches are unsatisfactory, particularly in relation to "technology push" projects for many reasons:

- The assessment criteria are usually not completely independent from each other; portfolios and those deriving from such decisions however, are all based on the orthogonality premise;

- The assessment processes are result-orientated designed and say nothing about the actual decision-making process; this however plays a critical role particularly in the early phases of development.

- The assessment criteria can usually only be described vaguely and therefore the portfolios that are derived from these are of limited help. Estimations and weightings of the criteria are done so under high uncertainty and interest and resource conflicts influence the result.

- The areas of potential application for the technology are usually still unknown; therefore market potential as well as any other quantitative data can not be derived from these values.

Alongside the methodical and application-related problems associated with the use of project portfolios, an internal viewpoint existed for a long time. The interest in "classical" portfolios has in the mean time waned due to the discussion of core competencies (Hamel/Prahalad, 1986). In place of the covering of the total value added chain, starting with research and development, production and (own-)marketing, as much as possible, companies today try to build core competency platforms upon the basis of their specific core. The early identification of potential partners with complementary competency structures is of great interest.

As an alternative to the classical portfolio analysis for the rough placement and first assessment of "technology push" projects, the viewing of the project within a competency portfolio framework is suggested (see Figure 4). Through this perspective, "technology push" projects are analyzed based on "contribution to the competency leadership" as well as "contribution to customer uses (market effectiveness)" criteria.

Insert Fig. 4 here

Figure 4: $\quad$ Assessment of "technology push" projects based on competency leadership and market effectiveness criteria (Source: Herstatt et al., 1996, pg. ) 
If this assessment should, for example, show that the company does not possess the required technological or marketing (core-)competencies in order to successfully introduce a technology-induced innovation into the market place, it will then suggest the procurement of these competencies via strategic partnerships and the establishment of relationship platforms.

The latent danger that prospective innovative technology projects may "disappear" from the $\mathrm{R} \& \mathrm{D}$ portfolio in a very early stage of the development because it doesn't (yet) succeed in recognizing attractive application areas and the derived market potential and future return-oninvestment, is lessened through this competency-based assessment. In this case, a "bottomup" approach can be pursued where the most varied of application areas in the technology being developed can be screened with respect to their core competencies. If this succeeds beyond division and company borders, then often completely new business types are created. For example: Phönix, an automobile industry supplier, developed, produced and distributed traditional rubber products for many different applications (e.g. tires, tubes, mufflers, seals etc.). The development planning was always carried out in each product group separately (R\&D portfolios of the divisions). Often, single projects with small volume contributions would be terminated in early stages; core competencies were not being thematically specified. Within the framework of a strategic project, they changed to searching for the common elements in each prospective R\&D project and to identify the specific competencies of the company. It became clear from this that all Phönix products were all related to sound dampening in automobiles. Based on this, a new business division, "acoustic management", was established, lacking competencies and key components were brought in, in the form of cooperations (e.g. with the company Freudenberg) or acquisitions and, through a new business (Vibrakustik AG), further expansion occurred. The development of the internal space acoustics of the "SMART" was in this way a significant reference project (see Figure 5).

\section{Insert Fig. 5 here}

Figure 5: Core competency-based "bottom-up" planning of the new business division "acoustic management" at Phönix AG

(Source: board presentation)

The following are examples of typical questions that a company may ask itself when in the early phases of technology's development, with reference, in particular, to potential development, production and marketing partners:

- Do we have a good understanding of the relevant sources of innovation in our industry?

- Which of our competencies and activities allow us to become involved in innovation in our industry?

- Do we access to authoritative people and companies who support our development projects?

- Who are the optimal partners for us for development project cooperations as well as any further value-added activities derived from these projects?

- What are the vision and strategy of these potential partners, and who are the reliable decision-makers (power promoters) as well as other important promoters (know-how, relationship) in these organizations?

- How can we best profit from the combination of internal and external competencies? 
The end result of such analyses leads not only to a good dynamic fit within the R\&D portfolio but also quite possibly to a architecture of the technology-make, buy and cooperation strategy that differs strongly from what currently exists. It may also pave the way for partnerships with companies with complementary competency fields.

\subsection{Close market proximity early on in the project and validation of the technology's relevance}

We have already discussed potential problems associated with the integration of customers and uses in the early phases of a technology's development in Section 3.2. The implications that come out of the work of von Hippels and his colleagues, in particular, strongly support the case for the early integration of especially well qualified customers. In this case, the narrow image of a customer should be discarded in preference of the term "Lead User". In the broadest sense of this concept, experts from analogous fields also come in to play here.

A possibility that derives directly from the Lead User model is the use of so-called analogous extreme users. This deals with users from analogous industries that operate under extreme conditions and, as a result, require special technological solutions. As these "solutions" may well not be available in the existing market as standard technology, the extreme users must become actively innovative themselves. If the same or similar functions are involved as in the technologies being developed by a company, then the identification of these extreme users and their integration into development activities could prove to be very useful.

A current example of this with Nortel (Nortel; 2000). The US company Nortel Networks is working at the moment on a GSM-based tracking system which should enable the remote activation of particular devices through the following of people or object's movements. As soon as a certain person at a certain time is detected going home, the activation of particular household devices begins (e.g. kitchen appliances are switched on, the bathtub is filled, the pre-heating of the sauna, the beginning of a cooking cycle etc.). In order to quickly convert this idea into concrete products, Nortel Networks identified a group of extreme lead users for whom "tracking" is of significant importance. In this way, people such storm trackers, big animal trackers or whale watchers, who had been involved in tracking activities for years. Due to suitable existing equipment simply not existing in this field, these people became innovative themselves and developed the required equipment in cooperation with component manufacturers.

The early identification of lead users or extreme users as well as their integration can, in our opinion, allow companies to carry out realistic technology explorations as well as building upon further goal oriented technology development. Despite this, till now only few companies employ such "exotic" methods.

\subsection{Reducing the development time through project-related "front loading"}

Much has been written in recent times in the innovation literature about the need to utilize competent, cross-functional project teams as well as the support of power, know-how and process promoters. We'll avoid at this point going into this in any further depth. An aspect that naturally plays an important role in technology-driven projects is the question, at which point in such projects should personnel from other functional departments, marketing/sales, production, service and customer management become involved. The general demand of as 
early as possible, often doesn't companies much further. Fujimoto, in particular, has pursued the theme for many years and calls for the "frontloading" of certain activities. By this, Fujimoto refers to a strategy that aims to result in the improvement of the development performance as well as a decrease in the development time through the systematic transplanting of problem solving processes that traditionally take place towards the end of the innovation process (e.g. design and security checks in automobile production) to earlier phases (Thomke/Fujimoto, 2000). For implementing this process, two approaches are usually discussed:

\section{(1) Project-related knowledge transfer}

In this case, knowledge generated from recently completed projects is systematically used for the problem solving processes of new projects. Development teams from companies such as Microsoft, for example, employ detailed "post mortems" after software development projects where, amongst other items, the type and source of problems are documented along with experiences made with the applied problem solving methods. Such project documentation supports then the teams working on current software developments. This "cross-project learning" is also particularly relevant for the technology-driven development projects where significant similarities in the abstract problem structure of such projects are to be seen. Typical of items that can be learnt from earlier projects items include:

- Which methods and processes were particularly well suited for the identification of a technology's application potential

- How new technologies can be transferred into innovative products and processes (search for an effective technology-transfer)

- At which stage of the technology development an (active) customer integration proves promising

- How research and development and marketing can effectively work together (search for an effective integration mechanism, effective integration-timing etc.).

\section{Early involvement of new communication and information technology in the product development process}

"Frontloading" means here, the "bringing forward" in the development process of potential problem fields from later innovation phases through virtual simulations and the carrying out of their analysis on a virtual basis. In this way, Toyota could identify security problems through virtual crash-test simulations in very early development phases that, in conventional proceedings, would only have been possible at a "real" prototype testing phase. With the help of these virtual crash-tests, Toyota could not only make significant cost savings and development time reduction (avoidance of the modification of a "real" prototype and re-test), but also increase the accuracy of the testing (it was possible to carry out crash analysis from different perspectives and at velocities). Virtual simulations are for technology-driven development projects particularly an excellent means to reduce technological and market uncertainties. An example of this can also be found in automobile development: fuel cell technology allows the development of automobiles with electrical, exhaust-free propulsion. Virtual simulations can provide developers with information in very early phases as to what implications the fuel cell technology has on the driving performance of the electrical automobile and what changes in design are required. A look into the development laboratories from Daimler-Chrysler and General Motors shows intensive work is being carried on the development of the electrical automobile utilizing virtual reality applications. Market uncertainty is reduced in this case through the "frontloading" of customer integration, where the customer, for example in the framework of "information acceleration" (see Section 3.3), is transplanted virtually into a future scenario of the new technology. 


\section{Conclusion}

Today's global competitive landscape possesses a greatly increased technology dynamic: new technologies that more often than not have a hybrid nature (e.g. biotechnology) replacing existing key and base technologies at an ever increasing rate. In this competitive environment technology-intensive companies have to develop the core competencies that allow the speedy realization of new technology concepts into innovative products and/or processes. A significant part of these core competencies lie in the process know-how, and, in this context, how project management can be effectively organized. Our discussion should show that the project management of technology-driven development projects must be orientated around the market-related characteristics of this project type. "Technology push" projects possess a very high market uncertainty that results from the uncertainty in potential application fields of the existing technology(ies), in that of potential market possibilities and customer needs within the individual application fields as well as in the uncertainty about potential competitors and the required infrastructure. For technology-intensive companies, this leads to the necessity to develop and implement intelligent mechanisms, processes and methods for the effective reduction of uncertainty. Only this way can they be sure that in place of "happy engineering", a technology-development is implemented that is orientated towards potential application fields and their market needs. Searching for the perfect recipe for reducing market uncertainty with technology-driven development projects effectively, both in the practice and in academic discussions will be done in vain. It is for this reason that our paper does not claim to deliver any such complete solution, rather more it should provide some stimulus for thoughts and discussion on this theme. 


\section{Acknowledgements}

We thank Dipl. Biotechn. Christian Müller at this point for his valuable assistance during the preparation for this article.

\section{Literature:}

Bleicher, K. (1991): Das Konzept Integriertes Management, Frankfurt a.M., New York.

Bower, J.L.; Christensen, C.M. (1995), Disruptive technologys: Catching the wave, in: Harvard Business Review, Vol. 73, Iss. 1, S. 43-53.

Chidamber, S.R.; Kon, H.B. (1994), A research retrospective of innovation inception and success: the technology-push, demand-pull question, in: International Journal of technology Management, Vol.9, No. 1, S. 94-112.

Cooper, R.C.; Kleinschmidt, E.J. (1990), New Products: The Key Factors in Success, American Marketing Association, United states.

Deszca, G.; Munro, H.; Noori, H. (1999), Developing breakthrough products: challenges and options for market assessment, in: Journal of Operations Management, Vol. 17, S. 613-630.

Groenfeld, P. (1997), Roadmapping integrates business and technology, in: Research technology Management, Vol. 40, Iss. 5, S. 48-55.

Hamel, G.; Prahalad, C.K. (1991), Corporate Imagination and Expeditionary Marketing, in: Harvard Business Review, Vol. 69, Iss. 4, S. 81-92.

Herstatt, C.; von Hippel, E (1992), From Experience: Developing New Product Concepts Via the Lead User Method: A Case Study in a „Low-Tech“ field, in: Journal of Product Innovation Management (9)

Herstatt, C.; Dockenfuss, R., (2000), Einsatz von VR-technologyn in den frühen Phasen des Innovationsprozesses, Hamburg, (Arbeitspapier in Vorbereitung).

Herstatt, C.; Brandes, W. (1991), Explorationsmarketing, in: Thexis, Jg. 8, Heft 6.

Kainzbauer, C.; Kaelber, C. (1998) Mannesmann Pilotdevelopment, in: Franke, N./von Braun, C.-F.: Innovationsresearch and technologymanagement, Berlin, Heidelberg, New York. 
Lender, F. (1991), Innovatives technology-Marketing: Grenzen der „konventionellen“ Marktresearchskonzepte and Ansätze zur methodischen Neugestaltung, Göttingen.

Lüthje, Chr. (1999): Kundenorientierung im Innovationsprozess: Eine Untersuchung der Customer-Hersteller-Interaktion in Konsumgütermärkten, Inaugural-Dissertation, LudwigMaximilians-Universität München, München (in Erscheinung).

Lynn, F.; Heintz, S. (1992), From experience: Where does your new technology fit into the marketplace?, in: The Journal of Product Innovation Management, Vol. 9, Iss. 1, S. 19-25.

Lynn, G.S. (1998), New product team learning: Developing and profiting from your knowledge capital, in: California Management Review, Vol. 40, Iss. 4, S. 74-93.

Lynn, G.S.; Morone, J. G.; Paulson, A.S. (1996), Marketing and discontinuous innovation: The probe and learn process, in: California Management Review, Vol. 38, Iss. 8, S. 8-37.

Nayak, R.; Ketteringham (1986), J.: Breakthroughs, New York.

Nortel Networks: Lead Users and Dynamic Information Transfer, Customer Paper 97010.06./06-00, Juni 2000

O'Connor, G.C. (1998), Market learning and radical innovation: A cross case comparison of eight radical innovation projects, in: The Journal of Product Innovation Management, Vol. 15, Iss. 2, S. 151-166.

Pfeiffer, S. (1992), technology-Frühaufklärung, Hamburg.

Rice, M.P.; O’Connor, G.C.; Peters, L.S.; Morone, J.G. (1998), Managing discontinuous innovation, in: Research technology Management, Vol. 41, Iss. 3, S. 52-58.

Rosenberger, P.J.; de Chernatony, L. (1995), Virtual reality techniques in NPD research, in: Journal of the Market Research Society, Vol. 37, Iss. 4, S. 345-355.

Shah, S. (2000), Sources and Patterns of Innovation in a Consumer Products Field: Innovations in Sporting Equipment, Sloan Working Paper \#4105, MIT Sloan School of Management.

Souder, W.E. (1989), Improving productivity through technology push, in: Research technology Management, Vol. 32, Iss. 2, S. 19-31.

Thomke, S.; Fujimoto, T. (2000), The effect of "front-loading" problem-solving on product development performance, in: The Journal of Product Innovation Management, Vol. 17, Iss. 2, S. 128-142.

Urban, G.; Weinberg, S.; Hauser, J. (1996), Premarket forecasting of really new products, in: Journal of Marketing, Vol. 60, Iss. 1, S. 47-60.

Urban, G.; Hauser, J.; Qualls, W.; Weinberg, B. (1997), Information acceleration: Validation and lessons from the field, in: Journal of Marketing Rsearch, Vol. 34; Iss. 1, S. 143-153. 
Veryzer, R.W. Jr. (1998 a), Key factors affecting customer evaluation of discontinuous new products, in: The Journal of Product Innovation Management, Vol. 15, Iss. 2, S. 136-150.

Veryzer, R.W. Jr. (1998 b), Discontinuous innovation and the new product development process, in: The Journal of Product Innovation Management, Vol. 15, Iss.2, S. 304-321.

Vinkemeier, R. (1999), Roadmapping als Instrument für strategisches Innovationsmanagement, in: technology \& Management, Jg. 48, S. 18-22.

Von Hippel,E.; Churchill, J.; Sonnack, M. (1998): Breakthrough Products and Services with Lead Users (unpublished Paper).

Von Hippel, E. (1988), Sources of Innovation, Cambridge (US).

Von Mirow, M. (1998) Innovation als strategische Chance, in: Franke, N./von Braun, C.-F.: Innovationsresearch and technologymanagement, Berlin, Heidelberg, New York.

Weyrich, C. (1996), Zentrale research and development als Speerspitze der internationalen Innovationsaktivitäten bei Siemens, in: Gassmann, O.; von Zedtwitz, M. (Hrsg.), Internationales Innovationsmanagement, München, S. 119-126.

Wood, S.C.; Brown, G.S. (1998), Commercializing nascent technology: The case of laser diodes at Sony, in: The Journal of Product Innovation Management, Vol. 15, Iss. 2, S. 167-183. 